\title{
EXPLORATORY STUDY A BRAZILIAN POPULATION WITH MULTIPLE CHRONIC CONDITIONS FROM THE PERSPECTIVE OF SMOKING
}

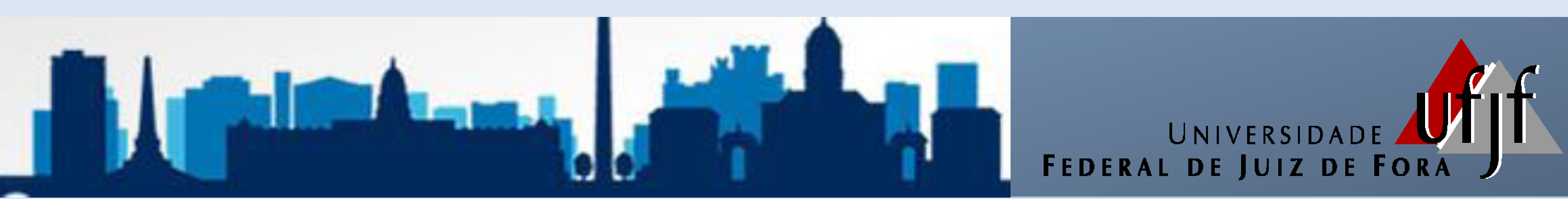

Arise Garcia de Siqueira Galil'1; Kimber P. Richter2; Eliane Ferreira Carvalho Banhato ${ }^{1}$; Tatiane da Silva Campos ${ }^{1}$; Rafael Henrique Almeida dos Santos'; Sonielle Albertino de Jesus Oliveira'; Marilaine Margarida de Souza';

Mariane Alves de Almeida'; Fernando A .B. Colugnati'; Ana Paula Cupertino²; Marcus Gomes Bastos'1.

Federal University of Juiz de Fora, Juiz de Fora, Minas Gerais, Brazil' ${ }^{1}$ Kansas University, Kansas City, Missouri, USA ${ }^{2}$

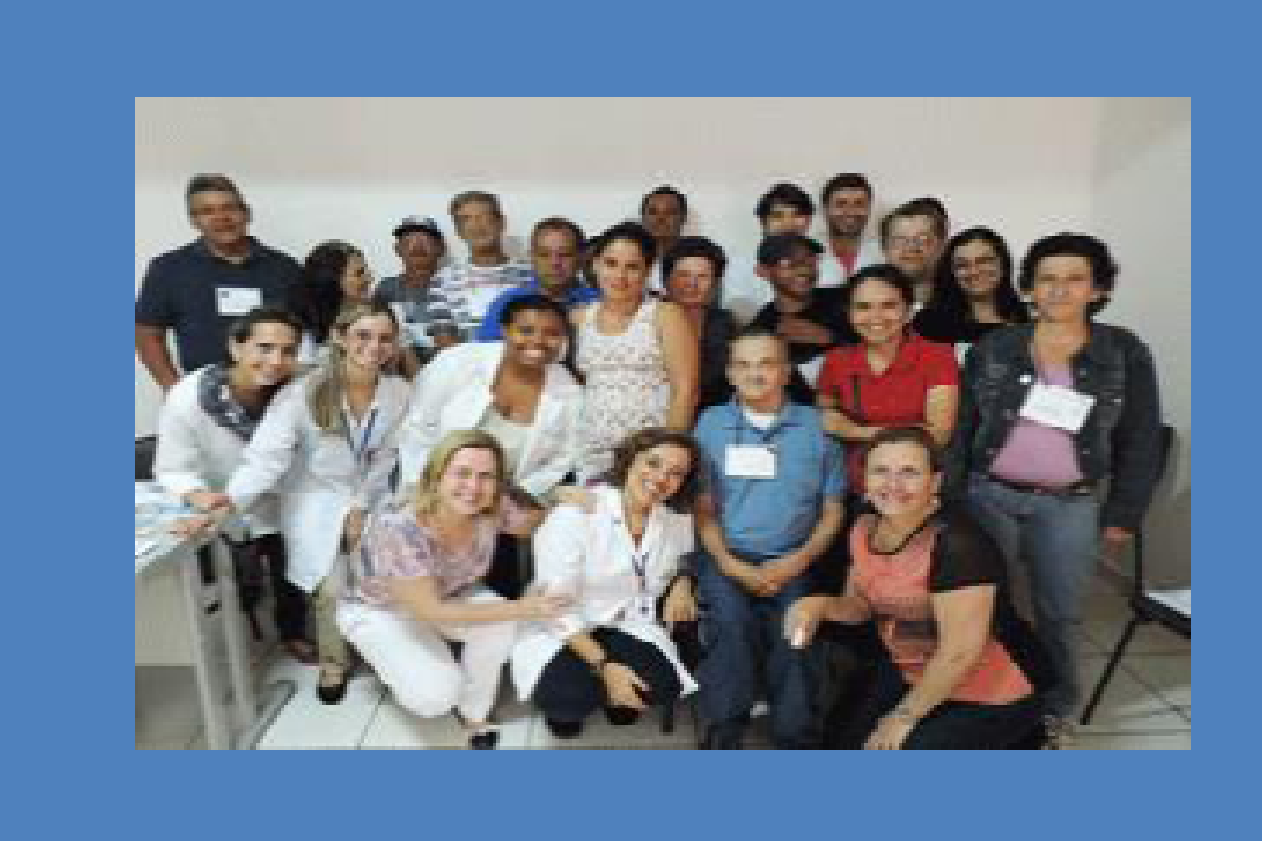

Introduction: Recent evidence shows that are modifiable risk factors and preventable, the most responsible for the high morbidity and mortality secondary to multiple chronic conditions (MCC), and smoking is one of the most important representatives. However, we still lack studies of populations with MCC and its association with smoking status. Objectives: To identify clinical and psychosocial characteristics according to the status of smoking among users with MCC, at high cardiovascular risk. Methods: Crosssectional study with evaluation of socio-demographic, clinical and laboratory data, in HIPERDIA Center Juiz de Fora, Minas Gerais (CHM-JF), Brazil, assisting users with MCC (hypertension, diabetes mellitus and chronic kidney disease). To check the status of smoking was considered smokers (S), former smokers (FS) and nonsmokers (NS). Control blood pressure (systolic blood pressure $<130 \mathrm{mmHg}$ ); metabolic (normal fasting blood glucose $<100 \mathrm{mg} / \mathrm{dl}$ and/ or regular glycated hemoglobin $<7 \%$, for users $<60$ and $<8 \%$ for those with $\geq 60$ years); Normal LDL-cholesterol $(<100 \mathrm{mg} / \mathrm{dL}$ ); chronic kidney disease absent, the glomerular filtration rate (GFR) $>60 \mathrm{ml} / \mathrm{min} / \mathrm{SC}$. Depression (PHQ-2 $\geq 3$ points) and alcohol abuse (AUDIT-C $>5$ points). Declared atherosclerotic disease, DAD (vascular damage documented, regardless of the affected territory).

Results: 1558 users reviews, of which $12 \%$ were S; $41 \%$ and $47 \%$, FS and NS.

Conclusion: The current smoking was more common in the younger population, sedentary, alcohol abuse, depressive symptoms, users declared atherosclerotic disease, COPD and a history of cancer. These data gave to $S$, a worse clinical profile compared to the NS. For despite the termination, the FS remained with similar comorbidities that active smokers.
Table 1: Baseline characteristics according to the status of smoking among users with multiple chronic conditions

\begin{tabular}{|c|c|c|c|c|}
\hline Variables & Smokers & $\begin{array}{l}\text { Former } \\
\text { smokers }\end{array}$ & $\begin{array}{l}\text { No } \\
\text { smokers }\end{array}$ & $p$ value \\
\hline Prevalence & $12 \%$ & $41 \%$ & $47 \%$ & $<0,001$ \\
\hline Women & $52,4 \%$ & $41,5 \%$ & $74,6 \%$ & $<0,001$ \\
\hline Age (years) & $56,2 \pm 12,5$ & $62 \pm 11,9$ & $60,2 \pm 14,8$ & $<0,001$ \\
\hline Low Education & $75,9 \%$ & $75,9 \%$ & $75,3 \%$ & 0,654 \\
\hline AH (self-report) & $92,4 \%$ & $92,5 \%$ & $91,9 \%$ & 0,920 \\
\hline DM2 (self-report) & $48,1 \%$ & $61,7 \%$ & $60,3 \%$ & 0,003 \\
\hline CKD (self-report) & $15,1 \%$ & $19 \%$ & $20,4 \%$ & 0,260 \\
\hline Normal Circumference abdominal & $40,8 \%$ & $32,8 \%$ & $21,8 \%$ & $<0,001$ \\
\hline Normal systolic blood pressure & $36,4 \%$ & $33,1 \%$ & $34,9 \%$ & 0,636 \\
\hline Normal blood glucose & $42,1 \%$ & $32,3 \%$ & $33,3 \%$ & 0,051 \\
\hline Normal glycated hemoglobin & $50 \%$ & $50,9 \%$ & $45,8 \%$ & 0,223 \\
\hline Normal LDL-cholesterol & $38,5 \%$ & $48,2 \%$ & $40,4 \%$ & 0,005 \\
\hline CKD absent & $58,9 \%$ & $65 \%$ & $61,9 \%$ & 0,258 \\
\hline Sedentary lifestyle & $81,6 \%$ & $69,8 \%$ & $70,3 \%$ & 0,005 \\
\hline Obesity & $32,6 \%$ & $43,2 \%$ & $50,5 \%$ & $<0,001$ \\
\hline Abuse of alcohol & $13,4 \%$ & $5,7 \%$ & $2,7 \%$ & $<0,001$ \\
\hline Depression & $44,9 \%$ & $30 \%$ & $32,7 \%$ & $<0,001$ \\
\hline COPD & $5,4 \%$ & $2,3 \%$ & $0,3 \%$ & $<0,001$ \\
\hline Asthma & $3,2 \%$ & $1,9 \%$ & $2,8 \%$ & 0,494 \\
\hline Previous cancer history & $2,2 \%$ & $3,1 \%$ & $1,7 \%$ & 0,240 \\
\hline Declared atherosclerotic disease & $26,5 \%$ & $27,1 \%$ & $19,4 \%$ & 0,002 \\
\hline
\end{tabular}

Where; $\mathrm{AH}=$ Arterial hypertension; $\mathrm{DM} 2=$ type 2 diabetes mellitus;

$C K D=$ chronic kidney disease $; C O P D=$ Chronic obstructive pulmonary disease 